\title{
SOURCES AND BENEFITS OF VITAMIN C
}

\author{
Krenaida Taraj, Asela Hasa, Alba Muca \\ University of Tirana, Faculty of Natural Sciences, Department of Chemistry \\ Contact address: krenaida.taraj@fshn.edu.al;
}

\begin{abstract}
Vitamin C is very important in the diet of each individual, so it is important to make each of us aware of the sources of Vitamin $C$ in the food products we consume, the recommended daily dose and cases of taking Vitamin $\mathrm{C}$ through supplements.Based on the processed data of the questionnaire we can say that $69 \%$ of the sample stated that they intend to get Vitamin C through the diet. Also, $43 \%$ of the sample say that they increase the use of food products which contain Vitamin C during the winter season in order to protect themselves from seasonal viruses. $74 \%$ of the sample stated that the presence of Vitamin $\mathrm{C}$ in certain food products influences their decision to consume certain food products. $51 \%$ of the sample stated that they would increase the consumption of products that contain Vitamin $\mathrm{C}$ as a result of the information they would have about the product. $64 \%$ of the sample stated that they have increased the consumption of food products that contain Vitamin C during the Covid-19 situation, and $43 \%$ of the sample stated that sometimes they intend to include in their children's diet products that contain Vitamin C.
\end{abstract}

Key words: Vitamin C; sources; benefit; food; supplement

\section{Introduction}

Vitamin C is very important for the protection of the organism, as it affects the increase of white cell production and the proper level of interferon (protein that plays an important role in the multiplication of viruses). When our immune system is weak then we are more vulnerable to colds, flu or even other even more serious health problems. It is observed that some nutrients, which are present in foods, are needed to strengthen the immune system naturally, while abuses in nutrients such as alcohol, sugar or diet in general, can weaken the immune system ${ }^{1-4}$. Vitamin 
$\mathrm{C}$ is known even as ascorbic acid and is a water-soluble vitamin. It is better to take Vitamin $\mathrm{C}$ daily with other supplements or food, because it is dissolved in water and delivered to the body tissues but it is not well stored ${ }^{5-6}$. The antioxidant benefits of vitamin $\mathrm{C}$ are also unclear. Vitamin $\mathrm{C}$ is potentially involved also in cancer and cardiovascular diseases prevention. Some studies on vitamin $\mathrm{C}$ show that it can be destroyed by light and heat during cooking the food.It is known that some kind of foods such e leaf beans contain a lot of non - heme iron and vitamin C improves a lot the adsorption of this type of iron ${ }^{7}$. Some studies show an association between low levels of vitamin $\mathrm{C}$ and the risk of heart disease; however, many studies have linked the use of vitamin $\mathrm{C}$ supplements to an increased risk of heart disease. The deficiency of Vitamin $\mathrm{C}$ (known as scurvy the main disease of severe vitamin $\mathrm{C}$ deficiency) can be shown by hair loss, loss of collagen, swelling or bleeding of gums, skin wounds, etc. Currently, even due to the global Covid-19 pandemic, attention has turned and intensified regarding the role of Vitamin C. There are few studies that show that high doses of vitamin $\mathrm{C}$ taken orally or (intravenously) prevent COVID-19. Studies show that consuming more vitamin $\mathrm{C}$ can increase the level of antioxidants in the blood by up to $30 \%^{8-11}$. This helps the body's natural defences to fight inflammation. It is very simple to meet the individual needs for vitamin $\mathrm{C}$ through food diet as long as you eat a variety of fruits and vegetablesVitamin $\mathrm{C}$ is found in many fruits and vegetables, including citrus, bell peppers strawberries, tomatoes, white potatoes, cruciferous vegetables $^{12}$. Studies show that is important to maintain a standard daily dose of Vitamin C, because taking beyond this amount may cause harmful affects on health. This dosage may be exceeded under medical supervision. Thedaily allowance for vitamin $\mathrm{C}$ isrecommended by Recommended Dietary Allowances (RDAs). Since it is usually advisable to take vitamin C from foods, many people turn to supplements to meet their needs. The daily value for vitamin $\mathrm{C}$ is different for each person according to the age, country, diseases, breastfeeding women, people who smoke etc ${ }^{13-16}$.

\section{Methodology}

\section{Study sampling}

The sampling of the study will aim to reflect an approach regarding the sources of Vitamin C and its benefits according to the perception of sampling. Measures taken by the government to prevent Covid-19 have reduced opportunities to move and physically access some sources of information, but in line with the object of the study we will focus on online information. In this respect, the sampling will consist of 200 (two hundred) citizens. The study also provides food products, their dosage and the presence of Vitamin $\mathrm{C}$, as well as the recommended daily dose for different categories of the population.

\section{Data analysis}

About 10 questions in the questionnaire were realized which are presented graphically below together with the answers for each of them. Regarding the first question of the study which aims to give an answer on the sampling gender, it results that $73 \%$ of the sample who answered the questionnaire questions belong to the female gender, and only $27 \%$ of the sampling belong to the male gender. The data are presented graphically, as in graph no.1. 


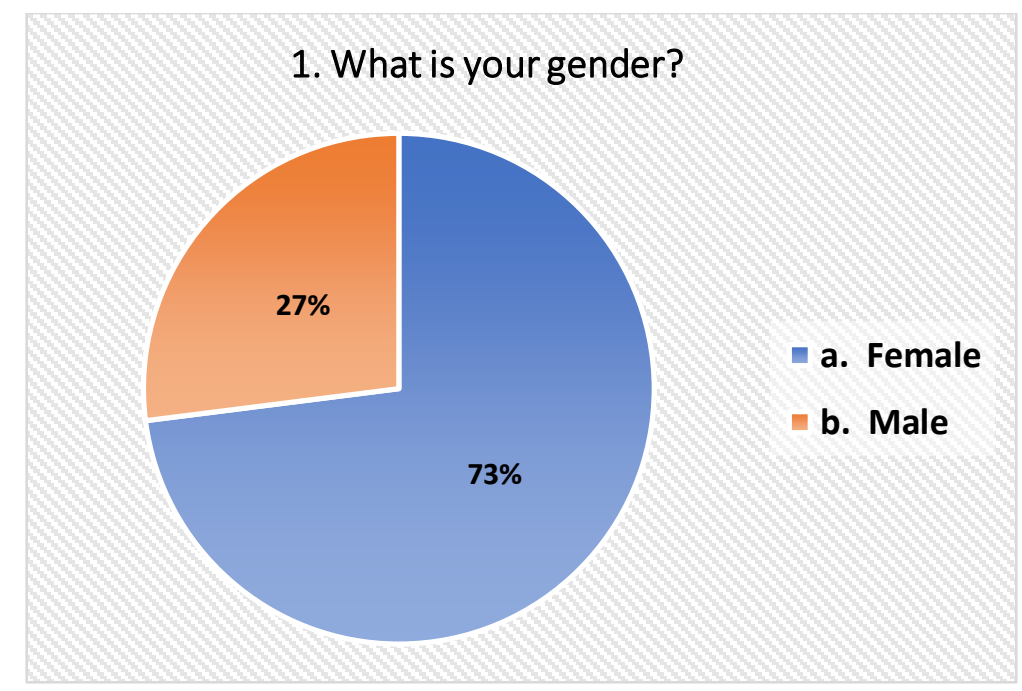

Graphic 1. Sampling gender

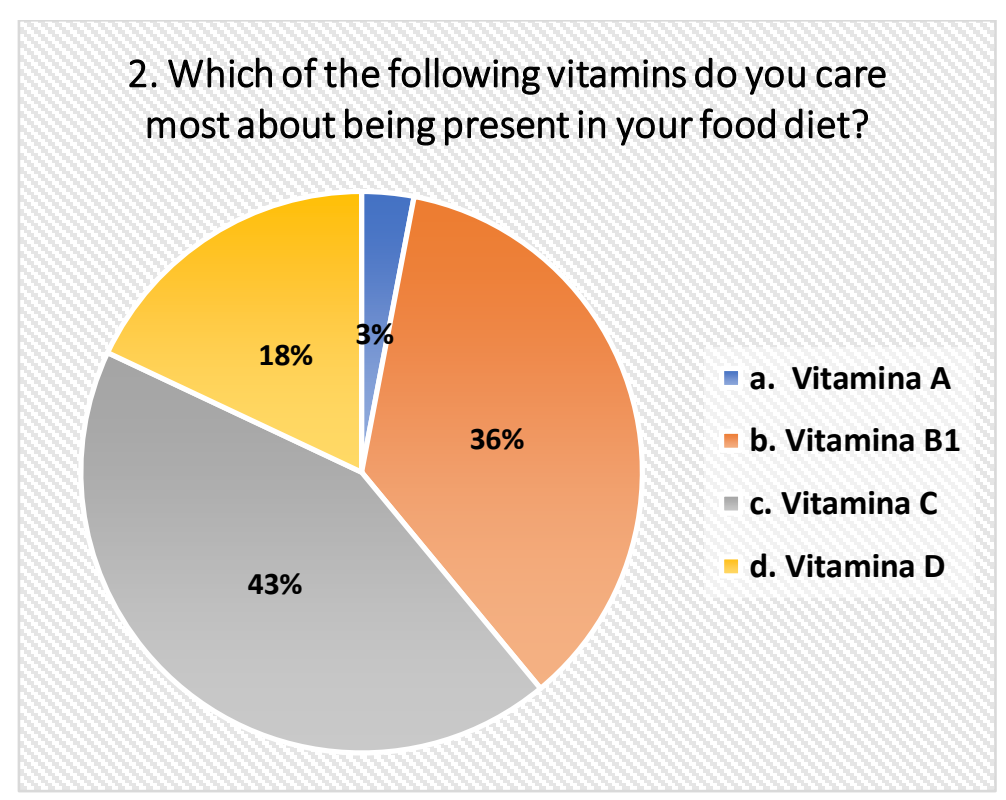

Graphic1. Which of the following vitamins do you care most about being present in your food diet? 


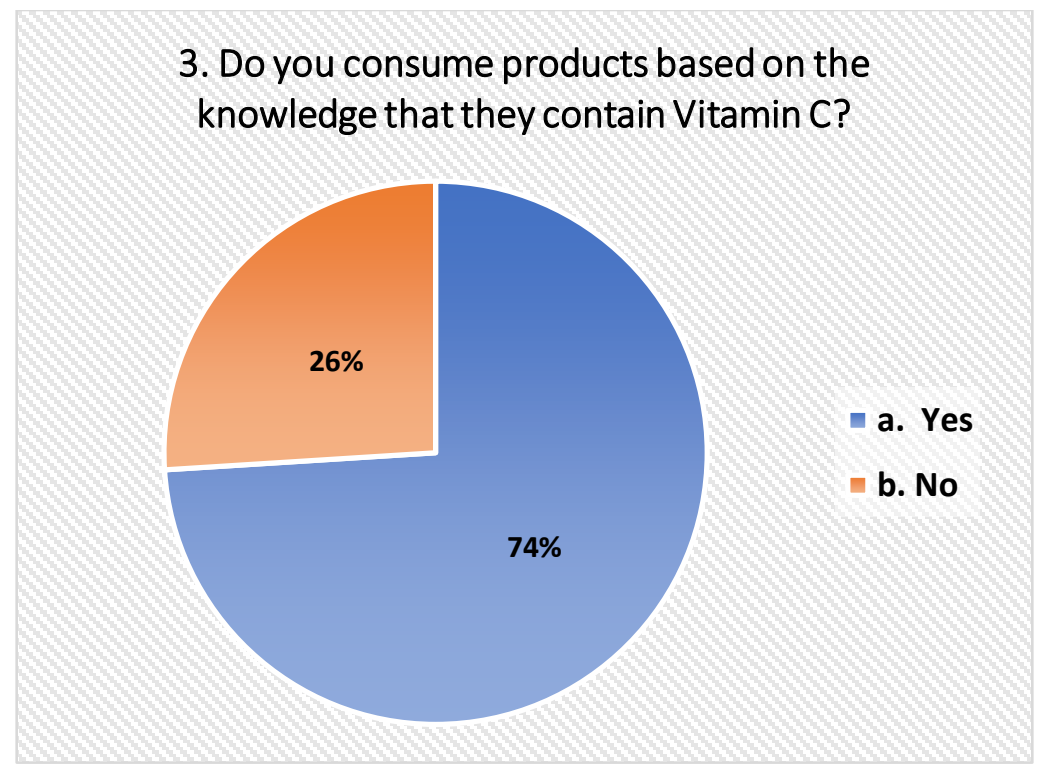

Graphic 2. Do you consume products based on the knowledge that they contain Vitamin C?

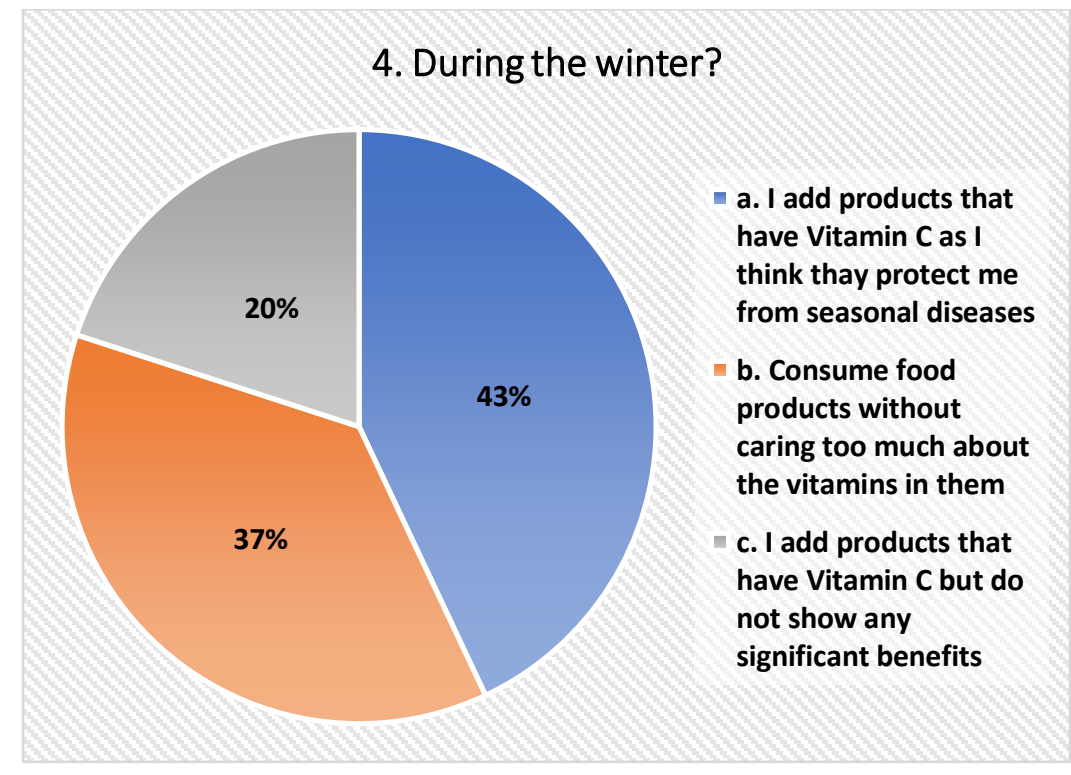

Graphic 3. Consumption of products which contain Vitamin $\mathrm{C}$ during the winter season (protection against seasonal viruses) 


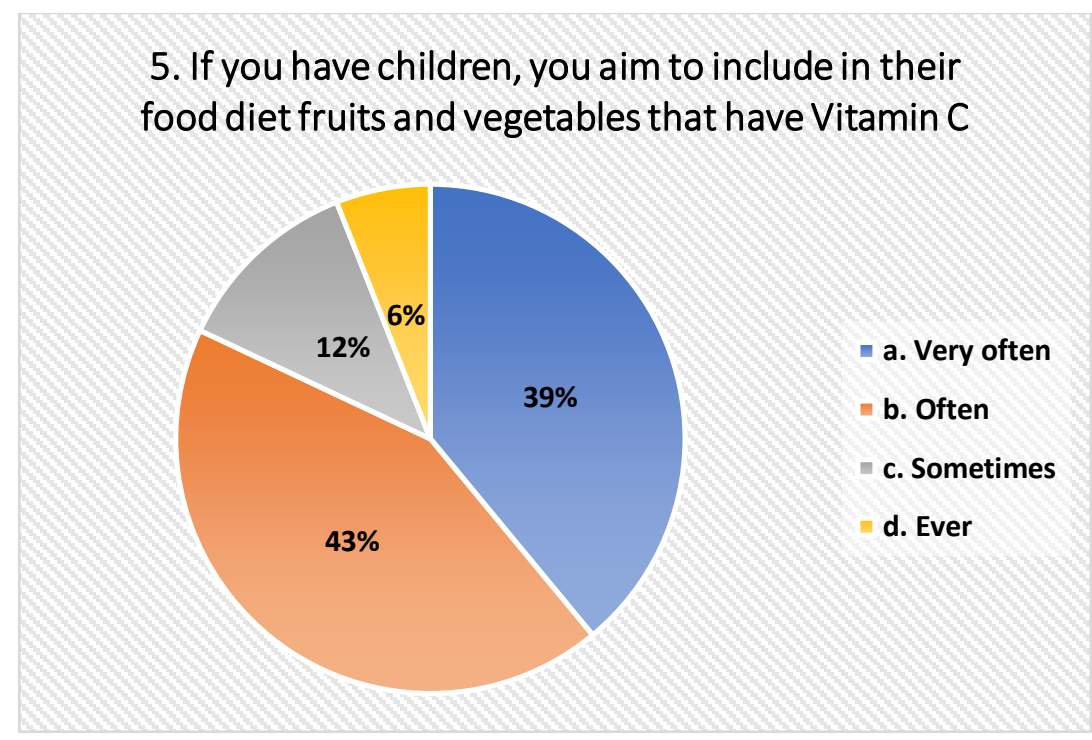

Graphic4. Sampling behaviour for the inclusion of products that contain vitamin $\mathrm{C}$ in the diet of their children

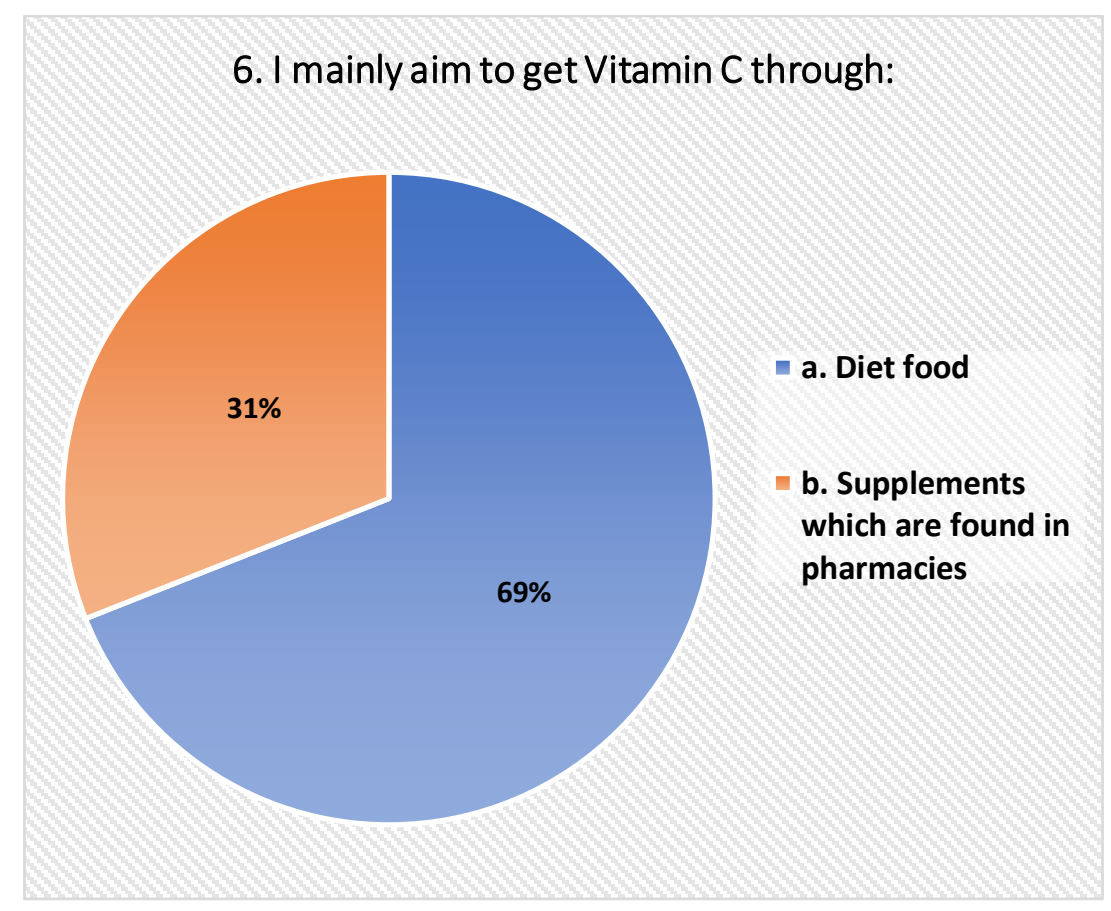

Graphic5. Source of Vitamin C 


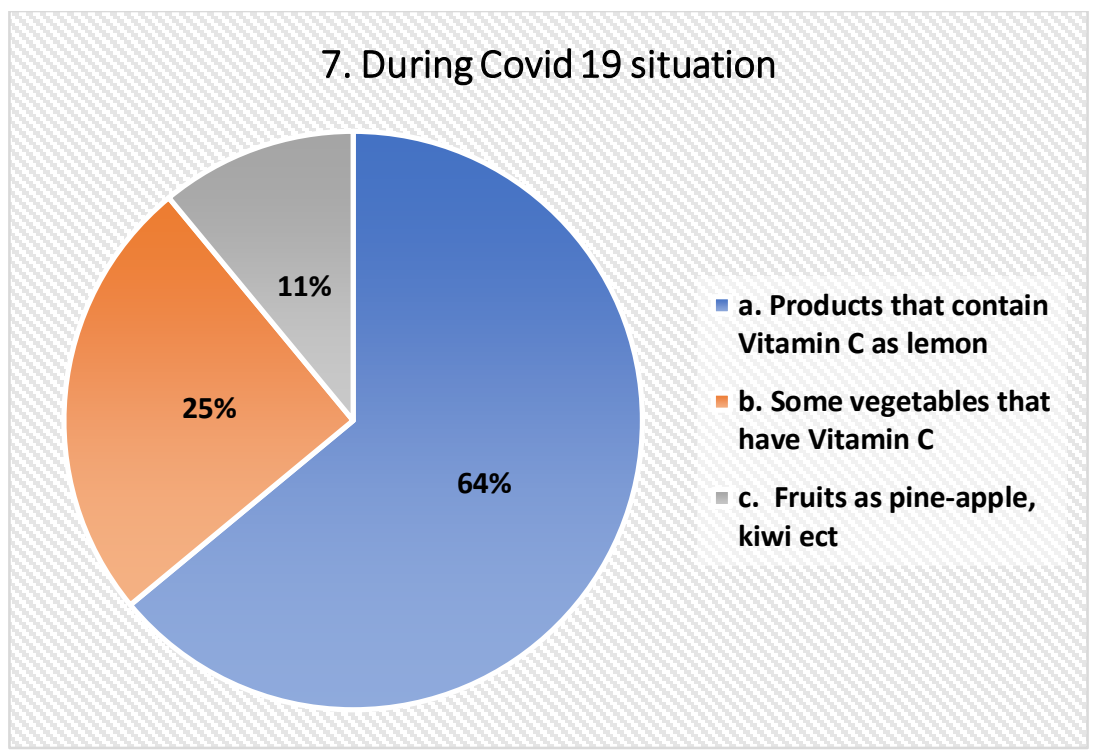

Graphic6. How has the situation of Covid 19 affected the addition of products which contain Vitamin C?

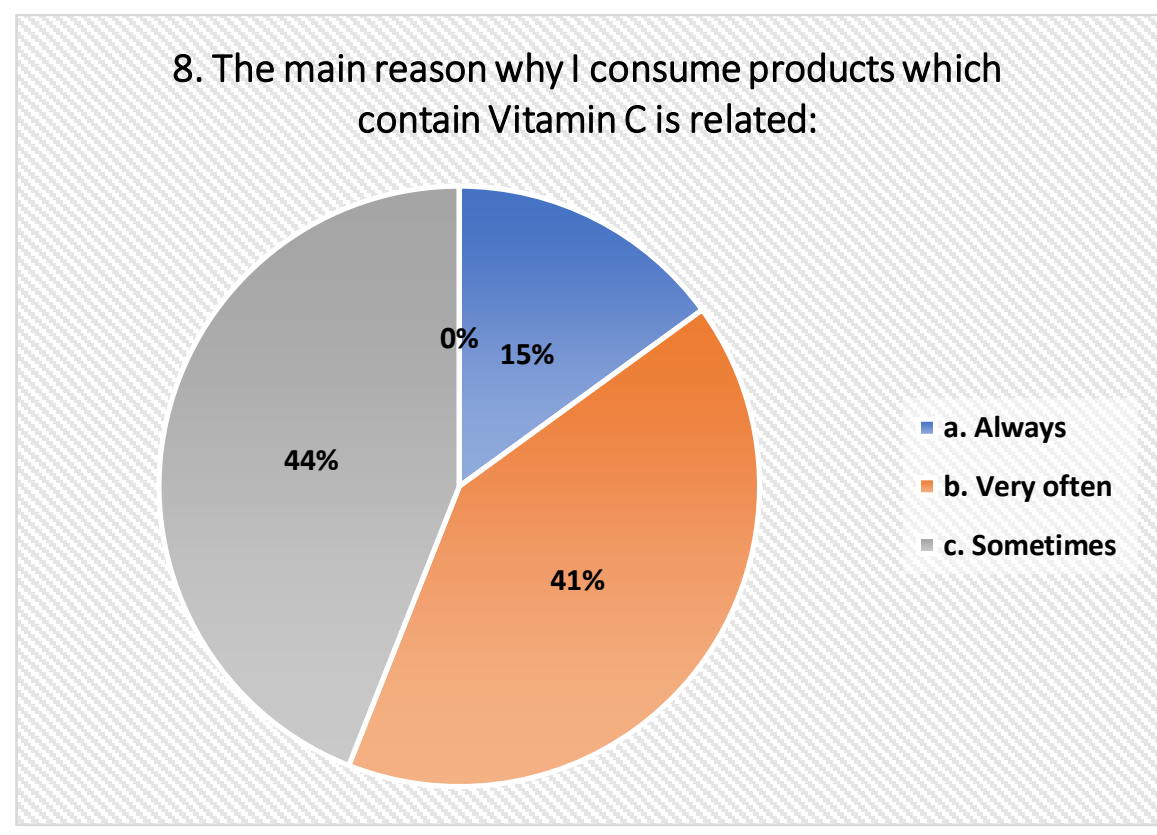

Graphic 7. What is the main reason that people consume products that contain Vitamin C? 


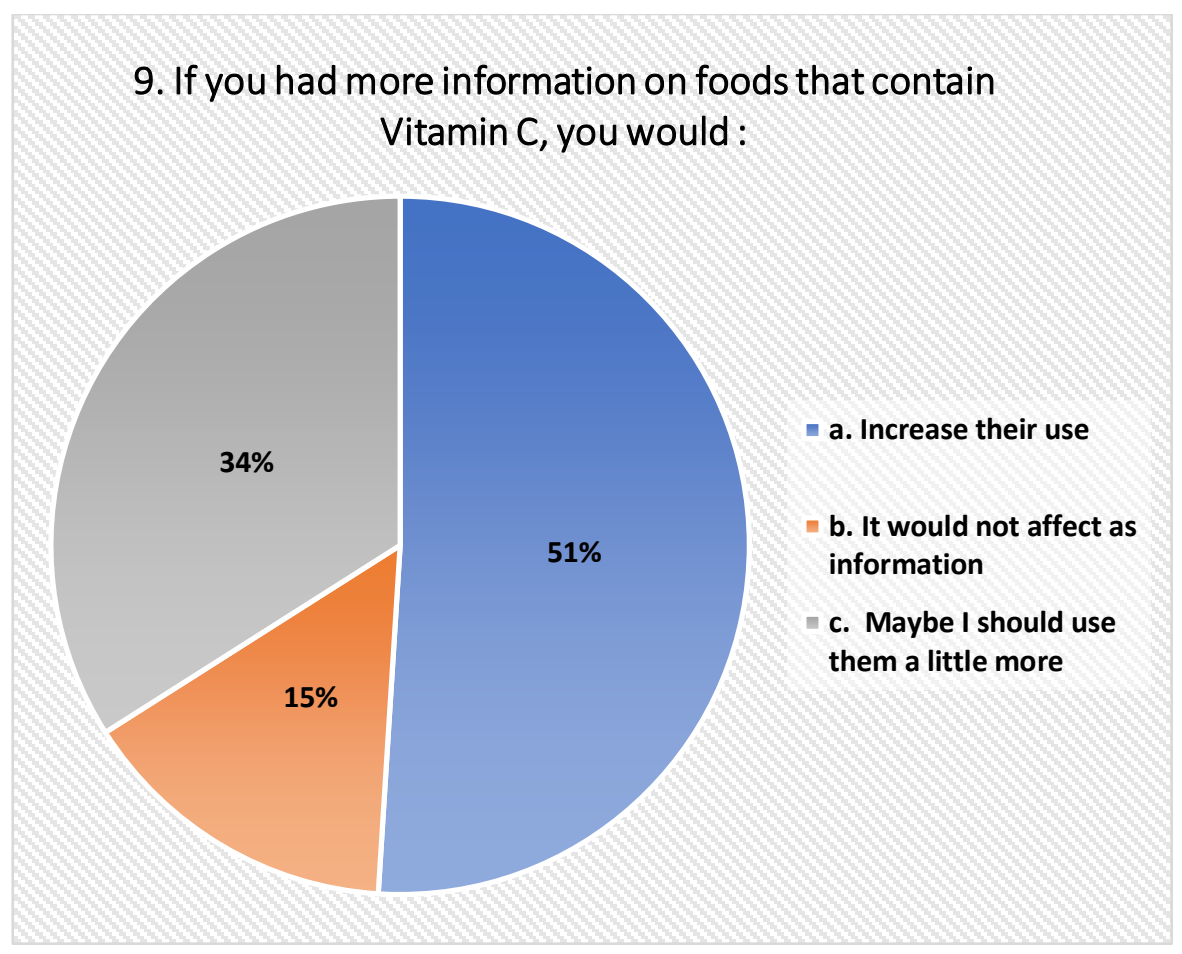

Graphic8. Need to have more information on Vitamin C sources

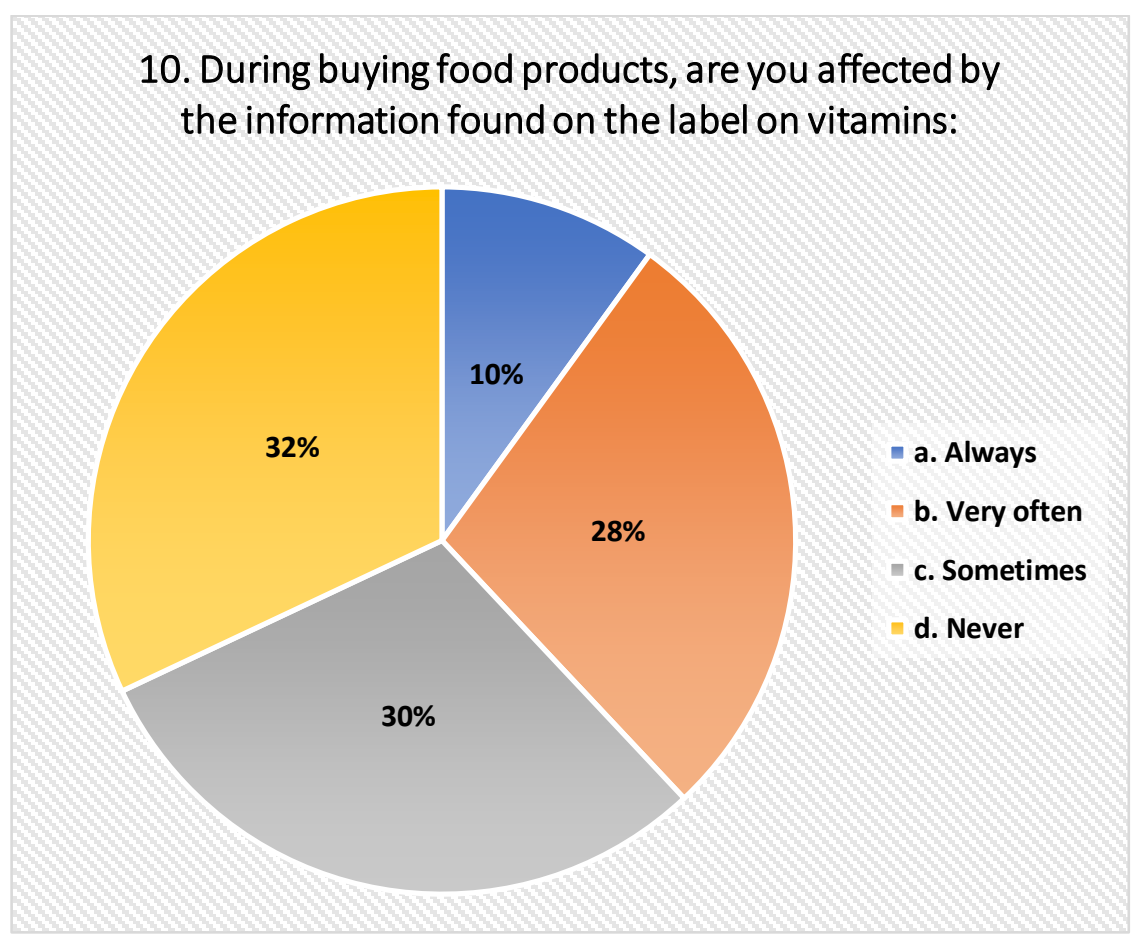

Graphic9. How much does the information on the label on vitamins affect when buying food products? 


\section{Conclusions}

It is import to provide sufficient amount of vitamin $C$ (in supplements and food) in countries that actually have deficiency of vitamin $\mathrm{C}$ and has no information how to use the supplements. Vitamin $\mathrm{C}$ affects the health of the patient and strengthens the immune system in several ways. Its antioxidant activity can reduce inflammation, which can help improve immune function. However, despite the benefits of vitamin C, studies have shown that use in high doses is not recommended as they can also cause side effects.Regarding the sources of Vitamin $\mathrm{C}$, the results of the questionnaire completed by sampling show that $69 \%$ of the sample states that they intend to get Vitamin $\mathrm{C}$ through diet. Also, $43 \%$ of the sample say that they increase the use of food products which contain Vitamin $\mathrm{C}$ during the winter season in order to protect themselves from seasonal viruses. $74 \%$ of the sample is expressed that the presence ofVitamin $\mathrm{C}$ in certain food products influences their decision to consume certain food products. $51 \%$ of the sample stated that they would increase the consumption of products that contain Vitamin $\mathrm{C}$ as a result of the information they would have about the product. 64\% of the sample stated that they have increased the consumption of food products that contain Vitamin C during the Covid-19 situation, and $43 \%$ of the sample stated that sometimes they intend to include in their children's diet products that contain Vitamin C It generally turns out that sampling has information generally on the sources and benefits of Vitamin $\mathrm{C}$ and based on its presented benefits aims to get vitamin $\mathrm{C}$ through diet mainly.

\section{Recommendations}

In order to increase the consumption of products which contain vitamin $\mathrm{C}$ it is recommended:

- To increase the information on the products that contain Vitamin C, starting from school age and also mentioning the reflection of this information in the labels of food products

- To consolidate the scientific views regarding the scientifically proven benefits as a result of consuming products which contain Vitamin $\mathrm{C}$.

\section{References}

1. Moser, M. A., \& Chun, O. K; Vitamin $\mathrm{C}$ and heart health: a review based on findings from epidemiologic studies.2016 International journal of molecular sciences, 17(8), 1328.

2. Naidu, K. A.; Vitamin $\mathrm{C}$ in human health and disease is still a mystery? An overview. 2003Nutrition journal, 2(1), 7.

3. Shailja Chambial, Shailendra Dwivedi, Kamla Kant Shukla, Placheril J. John, and Praveen Sharma; "Vitamin C in Disease Prevention and Cure: An Overview"; Published online 2013 Sep 1. doi: 10.1007/s12291-013-0375-3

4. JensLYkkesfeldt; "On the effect of vitamin $\mathrm{C}$ intake on human health: How to (mis)interpreted the clinical evidence", Redox BiologyVolume 34, July 2020,https://doi.org/10.1016/j.redox.2020.101532

5. Valdés, F. Vitamina C. Actas dermo-sifiliográficas, 2006 97(9), 557-568.

6. Sauberlich, H. E.; Pharmacology of vitamin C. Annual review of nutrition, 1994. 14(1), 371-391. 
7. Institute of Medicine (US) Panel on Dietary Antioxidants and RelatedCompounds. Dietary Reference Intakes for Vitamin C, Vitamin E, Selenium, and Carotenoids. Washington (DC): National Academies Press (US); 2000.

8. Poljšak B, Ionescu JG. Pro-oxidant vs. antioxidant effects of vitamin C. Handbook of Vitamin C Research: Daily Requirements, Dietary Sources and Adverse Effects (pp.153183). January 2009. Nova Science Publishers, Inc.

9. Lemon, S. C., Rosal, M. C., Zapka, J., Borg, A., \& Andersen, V.; Contributions of weight perceptions to weight loss attempts: differences by body mass index and gender. Body image, 2009, 6(2), 90-96.

10. K Akhilender Naidu; "Vitamin $\mathrm{C}$ in human health and disease is still a mystery? An overview"; Nutrition Journal volume 2, Article number: 7 (2003)

11. Jing Zhang, Xin Rao, Yiming Li, Yuan Zhu, Fang Liu, Guangling Guo, Guoshi Luo, Zhongji Meng, Daniel De Backer, Hui Xiang \& Zhiyong Peng; "Pilot trial of highdose vitamin C in critically ill COVID-19 patients"; Annals of Intensive Care volume 11, Article number: 5 (2021)

12. Wiseman M. The Second World Cancer Research Fund/American Institute for Cancer Research Expert Report. Food, Nutrition, Physical Activity, and the Prevention of Cancer: A Global Perspective: Nutrition Society and BAPEN Medical Symposium on 'Nutrition support in cancer therapy'. Proceedings of the Nutrition Society. 2008 Aug;67(3):253-6.

13. Food and Nutrition Board and Panel on Dietary Antioxidants and Related Compounds. Vitamin C. 2000;5:95-185. [Google Scholar]

14. Giuseppe Grosso, Roberto Bei, Diego Gazzolo; "Effects of vitamin C on health: A review of evidence"; June 2013 Frontiers in Bioscience 18(3):1017-29, DOI: $10.2741 / 4160$

15. Lopez-Varela, S., Gonzalez-Gross, M., \& Marcos, A.; Functional foods and the immune system: a review. 2002 European Journal of Clinical Nutrition, 56(3), S29-S33.

16. Mohanapriya, M., Ramaswamy, L., \& Rajendran, R. Health and medicinal properties of lemon (Citrus limonum). 2013 International Journal of Ayurvedic and Herbal Medicine, 3(1), 1095-1100 